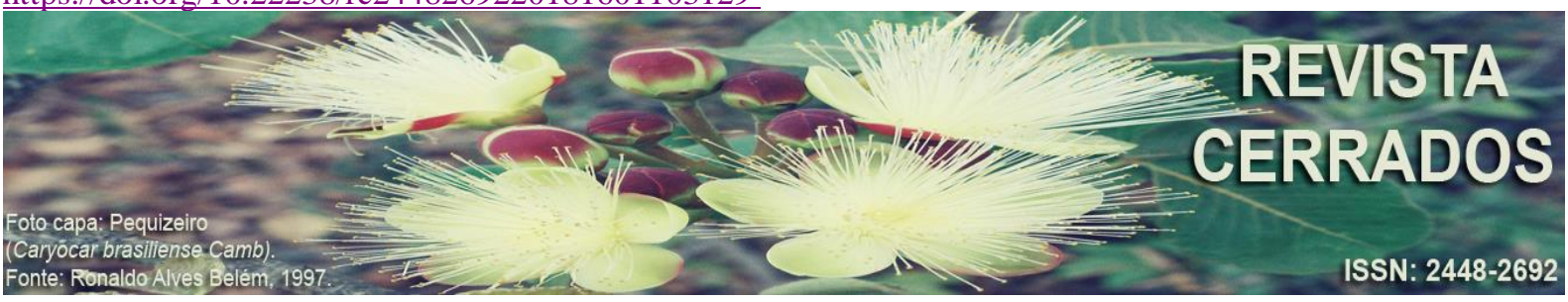

\title{
RISCOS GEOMORFOLÓGICOS E SENSITIVIDADE DA PAISAGEM NA BACIA HIDROGRÁFICA DO RIO PARATIBE (BHRP) - REGIAO METROPOLITANA DO RECIFE
}

\author{
LANDSCAPE SENSITIVITY AND MANAGEMENT \\ GEOMORPHOLOGICAL RISKS IN PARATIBE HYDROGRAPHIC \\ BASIN - PORTION OF THE MIDWEST REGION METROPOLITAN OF \\ RECIFE
}

\section{RISCOS GEOMORFOLÓGICOS Y SENSITIVIDAD DEL PAISAJE EN LA BACIA HIDROGRÁFICA DEL RIO PARATIBE (BHRP) - REGIÓN METROPOLITANA DE RECIFE}

\author{
Joana D'arc Matias de Almeida \\ Universidade Federal de Pernambuco - UFPE \\ E-mail: <joanamatiias@gmail.com> \\ Antonio Carlos da paz Rocha \\ Universidade Federal de Pernambuco - UFPE \\ E-mail: <antoniocprocha@yahoo.com.br>

Osvaldo Girão da Silva ID 9
Universidade Federal de Pernambuco - UFPE
E-mail: < osgirao@ gmail.com>

RESUMO

O estudo sobre riscos ambientais vem mais significância à medida que a ocupação dos espaços urbanos vem se intensificando e se adensando consideravelmente. Estes riscos têm uma relação direta com os fatores socioeconômicos, pois além das características naturais do espaço, o nível de exposição à vulnerabilidade de populações tem grande influência para tais situações. A área da bacia hidrográfica do rio Paratibe, localizada nos municípios de Paulista, Abreu e Lima, Olinda, Recife, Camaragibe e Paudalho está submetida a diferentes fatores de risco, diretamente relacionados com o tipo de ocupação de setores desta bacia, como encostas interfluviais e leitos fluviais. Mesmo a bacia tendo grande parte de sua área com ocupação incipiente, vários pontos estão sujeitos a processos que podem submeter um considerável contingente populacional ao risco. A partir da análise de mapas de declividade e altimetria, conjugados com o mapeamento da área urbanizada, foi realizada uma análise das 
ALMEIDA, J. D. M.; ROCHA, A. C. P.; SILVA, O.G.

Riscos geomorfológicos e sensitividade da paisagem na bacia hidrográfica do rio Paratibe (BHRP) - Região

Metropolitana do Recife

características e das alterações impetradas as encostas e aos canais fluviais, que causam, ou podem vir a causar intensificações de determinados tipos de eventos, os quais já resultam, e podem agravar, perdas materiais e até de vidas.

Palavras-chave: Riscos Geomorfológicos. Sensitividade da Paisagem. Bacias Hidrográficas.

\begin{abstract}
The study of environmental risks is gaining increasing significance as the occupation of urban spaces has been intensifying and increasing considerably. These risks have a direct relation with the socioeconomic factors, since besides the natural characteristics of the space, the level of exposure to the vulnerability of populations has great influence for such situations. The area of the Paratibe river basin, located in the municipalities of Paulista, Abreu e Lima, Olinda, Recife, Camaragibe and Paudalho, is subject to different risk factors, directly related to the type of occupation of sectors of this basin, such as interfluvial slopes and river beds. Even the basin having a large part of its area with rare occupation, several points are subject to phenomena, or processes, that can submit or submit a considerable population contingent to the risk. From the analysis of slope and altimetry maps, combined with mapping of the urbanized area, an analysis was made of the characteristics and alterations of the slopes and river channels that cause or may cause certain types of events or processes which already result, and can aggravate material losses and even lives.
\end{abstract}

Key-words: Geomorphological Risks. Landscape Sensitivity. Hydrographic Basin.

\title{
RESUMEN
}

El estudio sobre riesgos ambientales viene más significante a medida que la ocupación de los espacios urbanos se está intensificando y se adentra considerablemente. Estos riesgos tienen una relación directa con los factores socioeconómicos, pues además de las características naturales del espacio, el nivel de exposición a la vulnerabilidad de poblaciones tiene gran influencia para tales situaciones. El área de la cuenca hidrográfica del río Paratibe, ubicada en los municipios de Paulista, Abreu y Lima, Olinda, Recife, Camaragibe y Paudalho está sometida a diferentes factores de riesgo, directamente relacionados con el tipo de ocupación de sectores de esta cuenca, como laderas interfluviales y lechos fluviales. Incluso la cuenca con gran parte de su área con ocupación incipiente, varios puntos están sujetos a procesos que pueden someter un considerable contingente poblacional al riesgo. A partir del análisis de mapas de declividad y altimetría, conjugados con mapeamiento del área urbanizada, se realizó un análisis de las características y de las alteraciones impetradas a las laderas ya los canales fluviales, que causan, o pueden venir a causar intensificaciones de determinados tipos de eventos, los cuales ya resultan, y pueden agravar, pérdidas materiales e incluso de vidas.

Palabras clave: Riesgos Geomorfológicos. Sensibilidad del Paisaje. Cuencas Hidrográficas. 
ALMEIDA, J. D. M.; ROCHA, A. C. P.; SILVA, O.G.

Riscos geomorfológicos e sensitividade da paisagem na bacia hidrográfica do rio Paratibe (BHRP) - Região Metropolitana do Recife

\section{INTRODUÇÃO}

No Brasil, a percepção de risco geomorfológico advém da convivência com os processos naturais, sobretudo aqueles desencadeados por fenômenos climáticos, com ênfase para os pluviais, que devido à pressão populacional nas áreas urbanas ocasionam, eventualmente, desastres/catástrofes, com a geração de perdas e danos sociais, econômicos e ambientais à população.

O planejamento e gestão de riscos geomorfológicos tem se consolidado nos últimos anos devido à intensificação de processos erosivos, movimentos de massa, alagamentos, enchentes e inundações em áreas susceptíveis a tais processos, associados a densas ocupações de populações socialmente vulneráveis.

$\mathrm{Na}$ Região Metropolitana do Recife (RMR), as situações de riscos geomorfológicos envolvem, em sua maioria, deslizamentos de terra, alagamentos, enchentes e inundações, que decorrem da forma inadequada de ocupação de encostas e margens de rios e córregos, assim como pela ausência de uma rede de drenagem condizente com o escoamento produzindo quando de eventos pluviais extremos.

Para fundamentar os estudos voltados a riscos geomorfológicos em áreas urbanas faz-se necessário a organização de um arcabouço conceitual esclarecedor das categorias fundamentais como: desastre natural, risco, susceptibilidade e vulnerabilidade, a fim de evitar conflitos conceituais e fortalecer o debate sobre este tema tão recorrente em território nacional nas últimas décadas.

O presente artigo apresenta um breve debate teórico referente às categorias presentes na temática de risco geomorfológico, reforçando os estudos voltados à gestão de riscos analisados a partir da proposta integrada de sensitividade da paisagem, objetivando contribuir para com planos gestores eficientes e adequados para as especificidades de cada ambiente-trecho da bacia hidrográfica em questão. Por ser um estudo inicial, o foco será as características topográficas e o uso e ocupação da terra da bacia hidrográfica do rio Paratibe (BHRP).

Para efeito de estudo, a bacia hidrográfica analisada está inserida no núcleo urbano da Região Metropolitana do Recife (RMR) e engloba áreas dos municípios de 
ALMEIDA, J. D. M.; ROCHA, A. C. P.; SILVA, O.G.

Riscos geomorfológicos e sensitividade da paisagem na bacia hidrográfica do rio Paratibe (BHRP) - Região Metropolitana do Recife

Paulista, Abreu e Lima, Olinda, Recife e Camaragibe, mais o município de Paudalho, externo a RMR (Figura 1).

O rio Paratibe só recebe essa denominação na confluência do riacho da Mina com o riacho do Boi. Esses rios localizam-se sobre a unidade de paisagem dos Tabuleiros, estando inseridos nos limites municipais de Paudalho, Camaragibe e Paulista, em altitudes que podem ultrapassar 110 metros. Com extensão de aproximadamente 18 quilômetros, o rio Paratibe segue a direção preferencial oeste-leste até sua desembocadura no oceano Atlântico (CARVALHO, 2011).

Figura 1 - Localização da BHRP na RMR

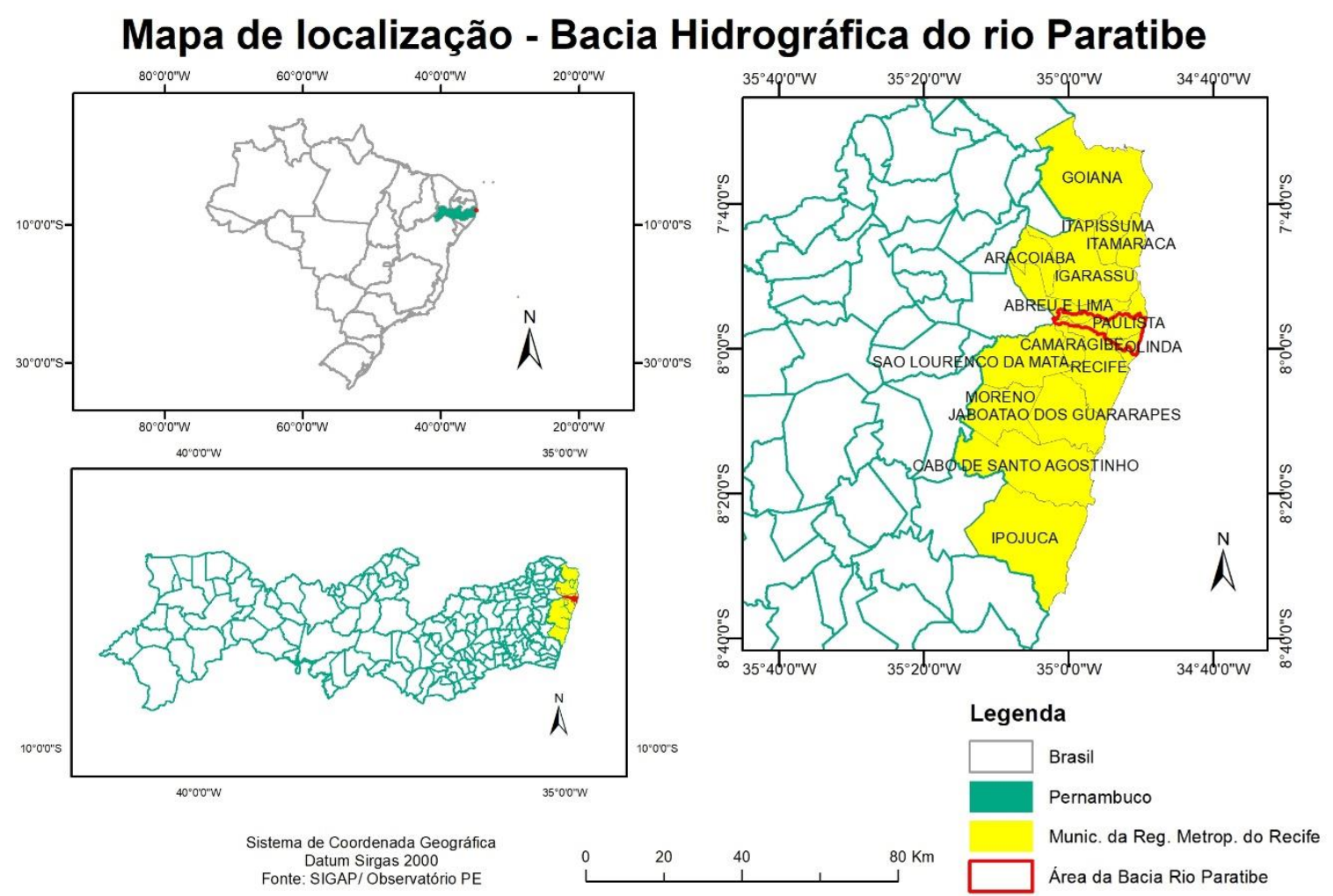

Fonte: Os autores.

A BHRP está inserida sobre os tabuleiros costeiros dissecados do seu alto curso até o início do médio curso, com pontos de maior altitude alcançando os 115 metros, estando tal compartimento estruturado sobre a Formação Barreiras. A partir do médio curso a morfologia da bacia sofre alterações, apresentando relevo mais dissecado, alternando entre colinas alongadas/amplas e colinas curtas, estas últimas apresentando formas arredondadas de 
ALMEIDA, J. D. M.; ROCHA, A. C. P.; SILVA, O.G.

Riscos geomorfológicos e sensitividade da paisagem na bacia hidrográfica do rio Paratibe (BHRP) - Região Metropolitana do Recife

topos convexos, e planícies aluviais. Tais feições derivam da proximidade com o litoral, que sofreu influência significativa da variação eustática do Holoceno, e consequente proximidade com o nível de base, que resulta em atuação maior de processos erosivos modeladores (CORREA, 2006; ROCHA, 2013).

As formas geomorfológicas presentes no médio curso são estruturadas também sobre sedimentos da Formação Barreiras, além da Formação Beberibe e sedimentos holocênicos. Já o baixo curso está inserido em uma planície flúvio-marinha holocênica, com predomínio de formas resultantes de ações fluviais e variação eustática holocênicas. Tal feição apresenta uma área ampla e aberta em direção ao oceano, semelhante a um anfi-teatro. Tal variação topográfica favorece o acúmulo de água no baixo curso, o que foi intensificado pelas formas de usos e ocupações por sítios urbanos densamente ocupados da RMR (SUGUIO, 2010).

O regime de chuva na área da bacia pode sofrer influências dos VCANs (Vórtices Ciclônicos de Altos Níveis) entre dezembro a fevereiro, excepcionalmente em março, da ZCIT (Zona de Convergência Intertropical) entre dezembro e maio e dos DOLs (Distúrbio Ondulatórios de Leste) entre março a agosto. Outros sistemas atmosféricos também causam chuva na região da bacia como as Brisas Marítimas, sistema de pequena escala advindo da costa e que pode adentrar ao continente, e Frentes Frias, ambos de sazonalidade de outonoinverno (março a agosto). Tal dinâmica resulta em uma média anual que varia entre 1.800 a 2.200 mm (GIRÃO, CORRÊA; GUERRA, 2006).

O elevado índice pluviométrico, intensificado e recorrente no outo-inverno, juntamente com as formas de uso e ocupação da bacia, respondem pelo desencadeamento de processos erosivos e hidrológicos intensificados na BHRP. Deriva-se também destas características pluviométricas, somada as elevadas temperaturas anuais e proximidade com oceano, a presença de resquícios da cobertura vegetal original de Mata Atlântica (Floresta Perenifólia Higrófila Costeira), vegetação de porte com grande variação de espécies, mas que, contudo, encontra-se pontualmente na BHRP devido à expansão urbana horizontal da RMR.

As características litológicas, e fitoclimáticas da BHRP resultam em solos profundos, como latossolos e argissolos, propensos a ações erosivas e a movimentos de massa, sendo estes intensificados pelo crescente adensamento ocupacional. 
ALMEIDA, J. D. M.; ROCHA, A. C. P.; SILVA, O.G.

Riscos geomorfológicos e sensitividade da paisagem na bacia hidrográfica do rio Paratibe (BHRP) - Região

Metropolitana do Recife

\section{Arcabouço conceitual das categorias de risco geomorfológico}

O reconhecimento das categorias que fundamentam os estudos voltados ao planejamento e gestão de áreas de risco geomorfológico embasa um debate conceitual objetivando formar uma base teórica e, concomitantemente, desmistificando dualidades. Eventos naturais, desastres naturais, riscos e vulnerabilidade, são categorias recorrentemente reportadas na temática da prevenção dos riscos decorrentes da dinâmica superficial, que passaremos a conceituar e caracterizar.

Um evento natural entende-se como um acontecimento natural, em que não são registradas perdas de cunho sociais e/ou econômicas, e que ocorre em decorrência da dinâmica do sistema físico, podendo ser ativado por agentes internos, como movimentos tectônicos geradores de terremotos e/ou tsunamis, ou agentes externos, como chuvas intensas e recorrentes desencadeadoras de movimentos de massa e/ou inundações (BITTAR, 1995; SILVA et al., 2017).

A categoria desastre natural é definida como um fenômeno natural que provoca danos/perdas (econômicas e sociais) devido à forma de ocupação e produção do espaço pelas atividades humanas (MOURA; SILVA, 2008). Assim, estes são decorrentes da ação humana, logo, não são eminentemente naturais. Os fenômenos naturais apenas terão impacto negativo sobre a sociedade na dependência de como esta se relaciona com o ambiente físico/natural através das formas de usos e ocupações da terra.

Portanto, um fenômeno natural estará relacionado a desastres quando houver a presença de ocupações humanas sujeitas a efeitos dos fenômenos naturais. A partir deste pressuposto, insere-se à discussão da categoria de risco natural, como a probabilidade de ocorrência de um fenômeno natural em determinada área, resultando em perdas/danos à população (VEYRET, 2007). Hétu (2003) se refere às áreas de risco, como áreas com a susceptibilidade que determinado fenômeno seja produzido, gerando danos/perdas em função da intensidade e do período de retorno.

Para Castro (2000) e Carvalho (2011) o risco é a probabilidade de ocorrência do perigo (susceptibilidade de um evento), mais o grau de prejuízo (vulnerabilidade) (Figura 2). $\mathrm{O}$ conceito de risco inclui a probabilidade de ocorrência, ou não, de um evento natural ou derivado antrópico, e a avaliação humana quanto aos seus efeitos nocivos/prejuízos 
ALMEIDA, J. D. M.; ROCHA, A. C. P.; SILVA, O.G.

Riscos geomorfológicos e sensitividade da paisagem na bacia hidrográfica do rio Paratibe (BHRP) - Região Metropolitana do Recife

(possibilidade de perdas). Neste caso, a avaliação qualitativa pode ser feita através da medição quantitativa de perda e probabilidade de ocorrência.

Moura e Silva (2008) admitem que os riscos apresentam-se em duas situações: a primeira refere-se a riscos decorrentes de fenômenos naturais de forte intensidade, porém de curta duração, mas com a capacidade de gerar efeitos catastróficos como, por exemplo, terremotos, tsunamis, erupções vulcânicas e furacões; a segunda trata-se de riscos decorrentes de danos cotidianos associados a fenômenos naturais sobre populações vulneráveis, como deslizamentos e inundações urbanas, ambos recorrentes em ambientes tropicais úmidos no Brasil.

Quando da possibilidade da ocorrência de um evento natural, tido como perigoso e capaz de produzir prejuízos para o espaço físico e social onde eles ocorrem, não só no momento da ocorrência, mas mesmo a longo-prazo, tem-se o chamado risco natural, sendo a percepção do perigo, resultante da vulnerabilidade natural e humana a eventos geofísicos (AYALA, 2002; BITTAR, 1995; VEYRET, 2007).

Figura 2 - Fatores geradores do risco

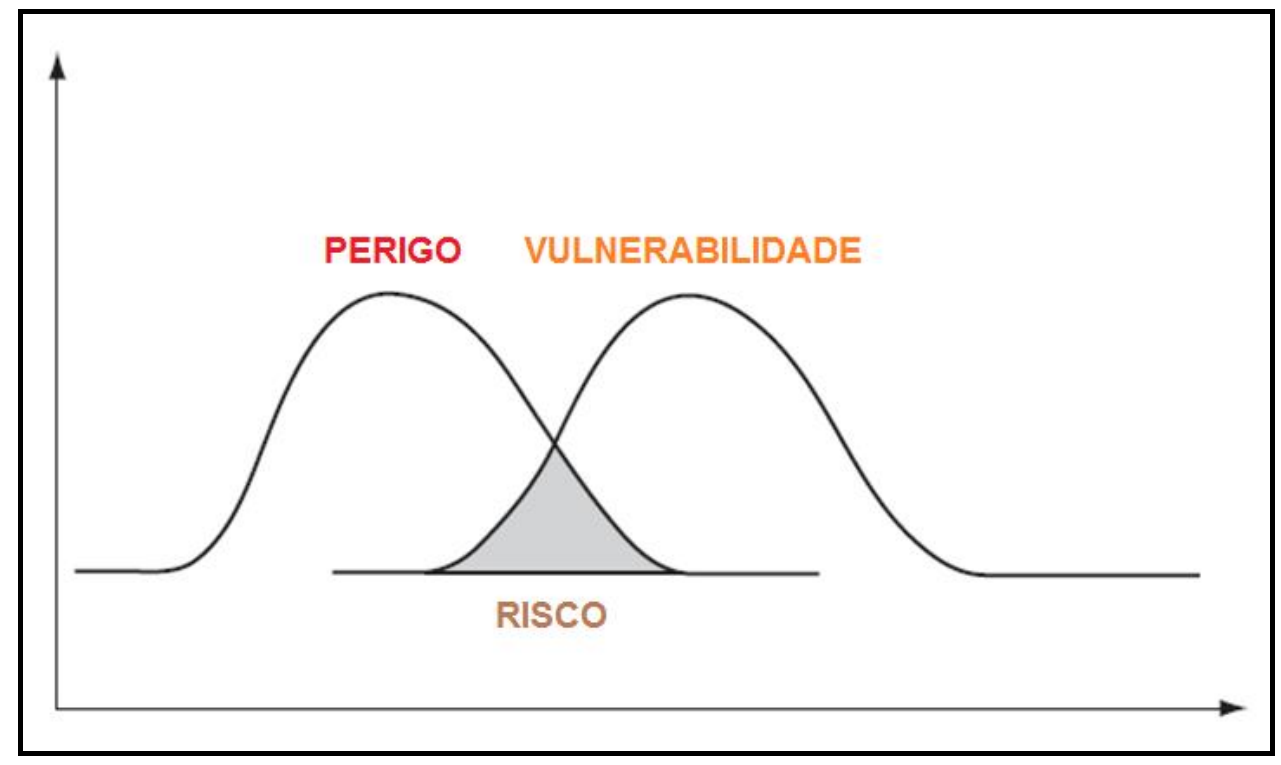

Fonte: Os autores.

Contudo, o termo "risco natural" tem sido questionado, pois esta formulação pode parecer ambígua, uma vez que o risco é necessariamente construído pela sociedade humana que, por exemplo, ao ocupar áreas susceptíveis a eventos naturais, se colocam em 
ALMEIDA, J. D. M.; ROCHA, A. C. P.; SILVA, O.G.

Riscos geomorfológicos e sensitividade da paisagem na bacia hidrográfica do rio Paratibe (BHRP) - Região Metropolitana do Recife

vulnerabilidade. Ao utilizar o termo "natural” enfatiza-se o processo, que está na origem da “construção do risco” por um grupo social (VEYRET, 2007).

Assim, a atuação das sociedades humanas constitui-se em uma forma de aceleração dos processos das dinâmicas naturais, dentre as quais as relacionadas à dinâmica superficial do relevo, uma vez que esta é superada por ações intensivas e extensivas praticadas ao ambiente físico em um curto espaço temporal quando da apropriação de terras para usos e ocupações diversas.

Quanto à gênese, os riscos naturais podem ser divididos em dois tipos, o de gênese endógena, quando relacionado às forças do interior da superfície terrestre, como terremotos, erupções vulcânicas e tsunamis; e de gênese exógena, quando condicionado por agentes externos, como movimentos de massa, processos erosivos e fluviais que, neste caso, estão relacionados com a dinâmica geomorfológica.

Para Gupta e Ahmad (1999), os chamados riscos de natureza especificamente geomorfológica relacionados a ambientes urbanos, por exemplo, podem ser avaliados segundo dois grupos:

1) Os riscos associados com a localização da cidade, ou parte dela, no caso se estão em áreas de encostas, planícies de inundação, deltas, ou mesmo em áreas sujeitas a ciclones tropicais;

2) Riscos originários ou acentuados pela utilização acelerada de recursos devido à dinâmica urbana, sendo exemplo à utilização de grande quantidade de águas subterrâneas de aquíferos arenosos com depósitos de argila quaternária.

A partir da ocupação de um determinado espaço, por exemplo, os para fins urbanos, às interações do sistema natural serão acrescidas facetas relativas à dinâmica social, quando a presença humana leva a aceleração de processos e, por conseguinte, às rápidas mudanças processuais de variadas magnitudes sobre o meio físico-natural.

Partindo-se deste contexto, o grau de exposição aos riscos depende de fatores socioeconômicos a que determinados segmentos das sociedades estão admitidos (HÉTU, 2003). As catástrofes não estão associadas simplesmente a fatores geográficos, como a localização dos eventos naturais, mas ao nível de exposição das populações, em geral mais 
ALMEIDA, J. D. M.; ROCHA, A. C. P.; SILVA, O.G.

Riscos geomorfológicos e sensitividade da paisagem na bacia hidrográfica do rio Paratibe (BHRP) - Região

Metropolitana do Recife

pobres, a estes eventos. Logo, é evidente que as populações de países de economia consolidada e aqueles emergentes ou em desenvolvimento se relacionam de modo diferente perante as situações de risco, devido à disponibilidade de tecnologia em planejamento e gestão que facilitam procedimentos de mitigação de catástrofes/desastres naturais. Ou seja, trata-se de diferentes vulnerabilidades das populações, que se traduzem não apenas em questões geográficas, mas também de organização política, de poder econômico e de estrutura social e cultural (CUNHA; DIMUCCIO, 2002).

Quanto à vulnerabilidade, este conceito está relacionado às condições sociais e ambientais a que as populações estão submetidas. Cunico e Oka-Fiori (2014) afirmam que o conceito de vulnerabilidade é de extrema complexidade, tratando-se das relações humana, física e social e, portanto, deve-se considerar para este aspectos físico-ambientais, técnicos, econômicos, psicológicos, sociais e políticos. Ou seja, a análise da vulnerabilidade gera a necessidade de compreensão integrada dos fenômenos naturais e dos elementos sociais expostos a estes (GARCIA; ZÊEERE, 2003).

Desta forma, a vulnerabilidade resulta de estruturas socioeconômicas que produzem precárias condições de vida em ambientes insalubres, sustentando uma situação de difícil recuperação. Neste ponto, Freitas et al. (2012), reforçam que os processos sociais tornam determinadas populações, sobretudo as mais pobres, em condições de vida e proteção social precárias, vulneráveis aos desastres/catástrofes, e que estas populações tendem a ocupar áreas de forte susceptibilidade a eventos naturais como inundações e movimentos de massa, o que as tornam mais vulneráveis diante da ocorrência de um evento natural, colocando-as em situação de perigo, como o resultado da vulnerabilidade natural e humana diante dos eventos naturais (GIRÃO et al., 2013).

\section{Sensitividade da Paisagem aplicada à gestão de riscos geomorfológicos}

No Brasil, os riscos naturais estão associados à dinâmica climática, que em torno de uma abordagem integrada da paisagem, torna-se fonte de energia (inputs) para sistemas naturais, desencadeando processos geomorfológicos, tais como, inundações e movimentos de massa, considerados os mais perigosos, intensos e recorrentes em nosso ambiente tropical úmido. 
ALMEIDA, J. D. M.; ROCHA, A. C. P.; SILVA, O.G.

Riscos geomorfológicos e sensitividade da paisagem na bacia hidrográfica do rio Paratibe (BHRP) - Região

Metropolitana do Recife

As inundações estão entre os fenômenos naturais mais recorrentes no mundo, afetando numerosas populações (HORA; GOMES, 2009). Para Ramos (2013) as inundações são fenômenos hidrológicos extremos de ordem natural ou induzidos pelas ações antrópicas. As inundações caracterizam-se pelo extravasamento de fluxo no canal fluvial devido ao excesso de precipitação, e/ou a presença de qualquer obstrução que impeça o fluxo de circular livremente no interior de um canal.

Já os deslizamentos são caracterizados como um dos tipos de movimentos de massa, comuns em ambientes de encostas tropicais úmidas no Brasil, como resultado da atuação de processos geomorfológicos ativados, geralmente, por intensas e recorrentes precipitações pluviométricas, sendo tais eventos gerados em diversas escalas espaciais e temporais, causando prejuízos materiais e, eventualmente, perdas de vidas humanas (FERNANDES et al., 2001).

Pensando no controle dos riscos geomorfológicos, sobretudo devido ao fato de inúmeras comunidades presentes em meios urbanos consolidados ou em consolidação se firmarem ao longo de terrenos alagáveis, de planícies de inundação e encostas íngremes, torna-se fundamental uma abordagem de prevenção e mitigação que identifique os elementos distribuídos espacialmente passíveis de gerar distúrbios na paisagem, potencializando os efeitos de inundações e deslizamentos. Ademais, deve-se considerar para tal controle a dinâmica climática geradora de eventos desestabilizadores, bem como as atividades antrópicas voltadas para formas de usos e ocupações.

Para tanto, a perspectiva sistêmica fornece um suporte relevante aos estudos ambientais integrados, baseados na troca de energia e matéria entre os compartimentos da paisagem, pois tal perspectiva visa compreender a relação processo-resposta na dinamização do modelado terrestre, definindo graus de estabilidade e/ou instabilidade em compartimentos geomorfológicos. Nesse ínterim, insere-se a ideia da sensitividade da paisagem, como a possibilidade de uma determinada alteração no controle do sistema ambiental, ou nas forças aplicadas a ele, sendo tal alteração produtora de respostas sensíveis, reconhecíveis, persistentes e complexas (BRUNSDEN, 2001; CORREAA, 2006; SOUZA, 2014).

Baseando-se em uma abordagem espacial sistêmica, Christofoletti (1999) expõe a necessidade da delimitação de um sistema, para que em relação a este possa ser realizada uma análise de sua estrutura e de seu comportamento. Levando em consideração esta assertiva, o 
ALMEIDA, J. D. M.; ROCHA, A. C. P.; SILVA, O.G.

Riscos geomorfológicos e sensitividade da paisagem na bacia hidrográfica do rio Paratibe (BHRP) - Região

Metropolitana do Recife

estudo em questão considera a bacia hidrográfica como recorte que possa englobar diversos aspectos ambientais, sendo eles naturais e/ou antrópicos. Para Suguio (1998, apud SOUZA, 2014), a bacia hidrográfica é uma parcela da superfície terrestre que compreende uma unidade de caráter espacial, ocupada por um sistema de drenagem ou que drena água para esse sistema.

Ao pensar em mudanças na evolução das paisagens, faz-se necessário compreender o comportamento dos sistemas ambientais, considerando as modificações nas forças (inputs) aplicadas sob o sistema, além de mudanças nas características próprias do sistema, sejam estas mudanças de ordem natural ou antrópica (SOUZA, 2014). Nesta perspectiva, a proposta da sensitividade da paisagem surge como suporte aos estudos voltados a mudanças ambientais que desencadeiam distúrbios na paisagem, gerando riscos à sociedade, principalmente as modificações em ambientes urbanos vulneráveis.

A ideia de sensitividade é sinônima de estabilidade da paisagem; uma relação entre a força de perturbação e a força de resistência (BRUNSDEN; THORNES, 1979). Ou seja, mudanças nas entradas (força de perturbação), seja por tectônica ou por eventos pluviais extremos, desestabilizam o sistema, sendo tais eventos relevantes para o entendimento das variações do comportamento da paisagem. No caso dos eventos pluviais extremos, como fator-controle, a precipitação afeta a natureza, a magnitude e a dinâmica do trabalho geomorfológico em uma bacia de drenagem (COELHO NETTO, 1998; SOUZA, 2011; ALMEIDA, 2015).

Assim, entende-se que a força de perturbação se refere à energia dos controles do sistema, como a dinâmica climática, a tectônica e mesmo o fator antrópico. Já a força de resistência trata-se da capacidade de um sistema resistir a alterações no seu estado inicial após perturbação (BRUNSDEN; THORNES, 1979; MATTOS; PEREZ FILHO, 2004).

Souza (2014) alerta para a distinção entre a força de perturbação e a modificação na resistência do sistema, de modo que, a retirada da vegetação de uma área não causaria a modificação no sistema geomorfológico, por exemplo, mas uma alteração na resistência desta área, tornando-a sensível aos processos erosivos. Portanto, a ação controladora da precipitação sob uma bacia de drenagem é potencializada pela força de perturbação de atividades antrópicas derivadas de formas de usos e ocupações, que contribui para a intensificação de processos erosivos e/ou deslizamentos em encostas (domínio interfluvial) e 
ALMEIDA, J. D. M.; ROCHA, A. C. P.; SILVA, O.G.

Riscos geomorfológicos e sensitividade da paisagem na bacia hidrográfica do rio Paratibe (BHRP) - Região

Metropolitana do Recife

erosão e/ou agradação nos leitos aluviais (domínio fluvial), devido ao adensamento de processos e formas antrópicas que reduzem a força de resistência.

A estabilidade da paisagem é entendida como a capacidade do sistema manter o seu padrão de organização após ser submetido a distúrbios e/ou mudanças impetradas por forças de perturbações (MATTOS e PEREZ FILHO, 2004). Apesar disto, a noção de estabilidade não deve estar atrelada ao estado estático, pois a paisagem permanece em constante transformação e renovação. Desta forma, a estabilidade é relativa e dinâmica. Phillips (2009) refere-se à visão de leigos quanto à paisagem imutável, com exceção as mudanças/alterações após catástrofes/desastres desencadeados pelas atividades antrópicas.

A paisagem torna-se não só mutável, como tem a possibilidade de recuperar-se após perturbação, mantendo seu padrão pré-perturbação ou próximo a ele. Isso diz respeito à resiliência, uma das formas de estabilidade, analisada com base em observações, reconstruções históricas, experimentos e modelos, que avaliam a resposta e a recuperação do sistema após perturbação (MATTOS; PEREZ FILHO, 2004; PHILLIPS, 2009). Outra forma de estabilidade é a resistência às perturbações, quando são mantidas as características estruturais e funcionais inalteradas diante das forças perturbadoras (MATTOS; PEREZ FILHO, 2004).

Para analisar o grau de estabilidade de um sistema atribui-se a existência de limiares, fundamentais para o entendimento das respostas frente a perturbações (PHILLIPS, 1992). A estabilidade é efetiva até um limite crítico, quando ultrapassado, o sistema perde a capacidade de retornar ao seu estado pré-perturbação ou de resistir aos distúrbios das forças perturbadoras.

Desta forma, a sensitividade da paisagem, como a relação entre a magnitude de mudança e resposta a estas mudanças, tem relação direta com a existência de limiares, pois quanto menor o limiar, maior a sensibilidade às perturbações e aumento da probabilidade de sair de seu estado de estabilidade (THOMAS, 2001; MATTOS e PEREZ FILHO, 2004). Neste ponto, a atribuição de limiares relacionados à sensitividade da paisagem diante de eventos pluviais extremos e atividades antrópicas excessivas em determinada área, torna-se indispensável na identificação de áreas de risco geomorfológico, viabilizando a aplicação da proposta de sensitividade da paisagem a estes fins. 
ALMEIDA, J. D. M.; ROCHA, A. C. P.; SILVA, O.G.

Riscos geomorfológicos e sensitividade da paisagem na bacia hidrográfica do rio Paratibe (BHRP) - Região

Metropolitana do Recife

A sensitividade de um sistema ambiental é definida por suas particularidades, que influenciarão na sua suscetibilidade a mudanças e/ou a pré-disponibilidade em absorver os efeitos das forças desestabilizadoras (BRUNSDEN, 1993; BRUNSDEN, 2001). De tal modo, a proposta de sensitividade da paisagem oferece uma análise sobre a capacidade de mudança e respostas dos sistemas geomorfológicos, baseada em informações de força e resistência; frequência, duração e magnitude das perturbações; estabilidade e resiliência, e características dos sistemas (PHILLIPS, 2009).

Portanto, o grau de risco geomorfológico pode ser dado a partir da sensitividade da paisagem. Para Phillips (2009), a evolução dos riscos geomorfológicos pode ser analisada a partir da evolução das mudanças/distúrbios e/ou das respostas dos sistemas geomorfológicos de acordo com alguns critérios espaciais e temporais. Para tanto, é necessário conhecer o comportamento do sistema ambiental e das relações entre os seus elementos.

Deste modo, considera-se, neste estudo, a bacia hidrográfica como objeto de análise e planejamento para a prevenção e mitigação de riscos geomorfológicos. A proposta de sensitividade aqui aplicada consistirá no mapeamento da altimetria, declividade e área urbanizada da bacia em tela, inter-relacionando estes fatores com intuito de compreender os aspectos responsáveis por eventos de riscos existentes em partes da bacia, e aqueles que podem vir a desencadear eventos semelhantes em outros pontos da bacia.

\section{Dinâmica processual em bacias hidrográficas urbanizadas}

Segundo Mattos e Perez Filho (2014), para compreender uma bacia hidrográfica como sistema não se pode realizar estudos isolados de seus componentes, pois sua compressão se dá a partir do entendimento da relação existente entre os elementos que a compõe, resultando em estruturas, funcionamentos e organizações distintas e complexas para cada bacia, não sendo, apenas, resultado do somatório destes elementos.

Assim, não se deve realizar análises individuais de elementos, pois se assim for feito não haverá uma compreensão da bacia como sistema e unidade complexa, como, por exemplo, analisar processos que ocorrem nos canais fluviais (domínio fluvial) à parte dos processos que ocorrem nas vertentes (domínio interfluvial), e vice-versa. 
ALMEIDA, J. D. M.; ROCHA, A. C. P.; SILVA, O.G.

Riscos geomorfológicos e sensitividade da paisagem na bacia hidrográfica do rio Paratibe (BHRP) - Região

Metropolitana do Recife

Partindo desse preceito de sistema, deve-se levar em consideração na análise dos riscos geomorfológicos a relação entre o relevo, tendo como foco as características de suas unidades como topo, encosta e vale; a litologia e a pedologia, considerando os tipos de rochas e solos e seus atributos como textura, porosidade, por exemplo; o clima e a dinâmica climática, no caso dos ambientes úmidos, responsáveis pelos grandes inputs de energia derivado do considerável índice de pluviosidade e suas recorrências; e a cobertura vegetal e o tipo de uso e ocupação da terra, considerando que estes dois últimos se inter-relacionam a partir dos processos de infiltração e escoamento, como também com a condição e viabilidade dos usos. Sabe-se que a água é o principal modelador do relevo em áreas úmidas, sendo responsável pelos principais tipos de riscos nas áreas urbanizadas do Brasil, desencadeando processos erosivos, movimentos de massa, enchentes, inundações e alagamentos.

Para Coelho Netto (1998) a precipitação é um importante fator, e ao mesmo tempo aspecto controlador, do ciclo hidrológico, e atua regulando as condições geográficas e ecológicas de uma determinada área. Ainda segundo a autora, a magnitude do trabalho geomorfológico da água está atrelada à quantidade relativa de precipitação, ou seja, o volume de chuva, à sua distribuição temporal, que pode ser em escalas diárias ou sazonais, e à intensidade das chuvas, razão entre o volume a duração.

O fluxo hídrico dentro de uma bacia hidrográfica, que influencia na dinâmica geomorfológica, ocorre basicamente de duas formas: pela infiltração e pelo escoamento. A infiltração da água depende das características litológicas, pedológicas, da cobertura vegetal e do uso e ocupação da terra. A água infiltrada flui lateralmente, podendo exfiltrar nos canais fluviais, abastecer os lençóis freáticos e nascentes, como também pode sofrer processo de evaporação, retornando para atmosfera (GUERRA, 1999).

A água que escoa sobre a superfície, seja de forma difusa ou concentrada, é responsável pela modelagem do relevo a partir dos processos de morfogênese e morfodinâmica, sendo os processos responsáveis pela alteração do modelado em áreas tropicais os processos erosivos hídricos e os movimentos de massa. Estes processos também estão atrelados a situações de riscos geomorfológicos, já que os mesmos retrabalham o material superficial, o que muitas vezes resultam em mudanças no comportamento dos canais. Os processos erosivos originam perda de solo e feições erosivas, as quais podem desestabilizar construções direcionadas a atividades extrativistas, agropecuárias, industriais, 
ALMEIDA, J. D. M.; ROCHA, A. C. P.; SILVA, O.G.

Riscos geomorfológicos e sensitividade da paisagem na bacia hidrográfica do rio Paratibe (BHRP) - Região Metropolitana do Recife

residências e comerciais, e contribuem para a deposição de sedimentos nos canais fluviais, assoreando-os. Os movimentos de massas, além de originar os mesmos efeitos dos processos erosivos, causam também efeitos mais diretos, como destruição dos mais diversos tipos de construções (com variados usos) e acidentes envolvendo vítimas, eventualmente fatais (GUERRA, 1999; GIRÃO et al., 2013).

Todo o material removido pelos processos erosivos e movimentos de massa tem como destino o nível de base, que variando de escala, pode ser o sopé da encosta, o canal fluvial e o oceano. Esse material ao ser depositado pode afetar a dinâmica fluvial da bacia, devido ao preenchimento verticais e laterais do canal, diminuindo o espaço de vazão da água. Como resultado, a água se destina a pontos os quais normalmente não eram atingidos.

Contudo, a de se considerar que tais processos são normais à dinâmica natural, independente de ações antrópicas. No entanto, quando a ocorrência se dá em ambientes ocupados por populações, seja ela rural ou urbana, os efeitos podem ser danosos a ambos (ambiente físico/natural e população). Com os canais preenchidos o nível dos rios se eleva e em momento de maior entrada de energia, como os períodos chuvosos, o aumento da vazão resulta no extravasamento dos limites normais (leito maior sazonal) atingidos pelos rios, alcançando o leito maior excepcional (CHRISTOFOLETTI, 1980; SUGUIO, 2003).

\section{Procedimentos metodológicos}

Neste ensaio foram cruzadas informações obtidas com o mapeamento e análises no software ArcGis 9.3, com dados obtidos no trabalho de campo. O trabalho de gabinete consistiu no mapeamento da área de estudo a partir da criação de MDEs (Modelo Digitais de Elevação), utilizando dados SRTM (Shuttle Radar Topography Mission) com resolução de 30 metros, obtidos através do programa Brasil em Relevo da EMBRAPA. De posse dos dados, os procedimentos iniciais foram o preenchimento das depressões e a retirada dos picos apresentadas no MDE, utilizando a ferramenta fill sinks do ArcGis 10.3. Posteriormente foram elaborados os mapas declividade (usando a ferramenta slope - dentro do módulo surface na extensão Spatial Analist Tools) e acumulação de fluxo (através da ferramenta flow accumulation dentro do módulo hydrology na extensão Spatial Analist Tools). 
ALMEIDA, J. D. M.; ROCHA, A. C. P.; SILVA, O.G.

Riscos geomorfológicos e sensitividade da paisagem na bacia hidrográfica do rio Paratibe (BHRP) - Região

Metropolitana do Recife

A partir dos dados de declividade, foi possível analisar os pontos mais propícios a sofrerem processos erosivos e gravitacionais, assim como as encostas que tem maior contribuição no fluxo superficial e de sedimentos devido a maior angulação das mesmas. $\mathrm{O}$ mapa de acumulação de fluxo nos fornece os pontos onde há concentração resultante do fluxo hídrico superficial, denotando os pontos favoráveis a enchentes e inundações. Cruzando essas informações com mapas de uso e ocupação da terra (elaborados com uso do software livre Google Earth Pro e o Arc Gis 10.3), e com a confirmação no trabalho em campo, foi possível apontar os pontos mais suscetíveis a sofrerem os processos acima mencionados.

O trabalho de campo foi realizado em 17/02/2018 e abarcou pontos especificados nas figuras do texto. Foram visitados os pontos mais críticos previamente analisados durante o mapeamento da área, como pontos de maior declividade, acumulação de fluxo e áreas ocupadas com diferentes intensidades de adensamento. Em campo foram averiguadas ocupações e intervenções nas encostas, como arruamentos e galerias pluviais em direção ao vale e intervenções inacabadas nos canais fluviais.

\section{Avaliação dos riscos e sensitividade da BHRP}

A bacia hidrográfica analisada é de pequeno porte, com área de $118 \mathrm{Km}^{2}$, com a maior parte localizada no interior da Região Metropolitana do Recife. Possui pouco mais de 50\% da área urbanizada (CARVALHO, 2011). Contudo, parte considerável da ocupação urbana ocorre em áreas suscetíveis a inundações e, em alguns locais, propensos a movimentos de massa.

No limite oeste da BHRP, em seu alto curso, existem ocupações com fins residenciais em áreas periurbanas, que não apresentam infraestrutural viária e de saneamento básico em áreas interfluviais na margem direita do rio sobre áreas de tabuleiros (Figura 3), estando tais ocupações em bordas de tabuleiros.

Este tipo de ocupação de caráter residencial demanda vias de acesso que, invariavelmente, são criadas a partir de caminhos para transeuntes que, com a contínua utilização, leva a selagem do solo e a consequente débil infiltração em benefício da potencialização do escoamento superficial direcionado, propício ao desenvolvimento de feições erosivas lineares como ravinas e seu estágio avançado na forma de voçorocas. 
ALMEIDA, J. D. M.; ROCHA, A. C. P.; SILVA, O.G.

Riscos geomorfológicos e sensitividade da paisagem na bacia hidrográfica do rio Paratibe (BHRP) - Região Metropolitana do Recife

De acordo com Brunsden (2011), a gênese e evolução do processo erosivo atua como força de perturbação para tais ambientes, alterando a força de resistência do sistema, o que pode desencadear alteração no mesmo a partir da intensificação do processo de erosão regressiva, que pode modificar o nível de base, criando novos knick point (quebras de declive) que pode acentuar o processo erosivo.

Figura 3 - Erosão regressiva na borda do tabuleiro em margem de arruamento (rua dos Mineiros, bairro de Aldeia dos Camarás, Camaragibe-PE)

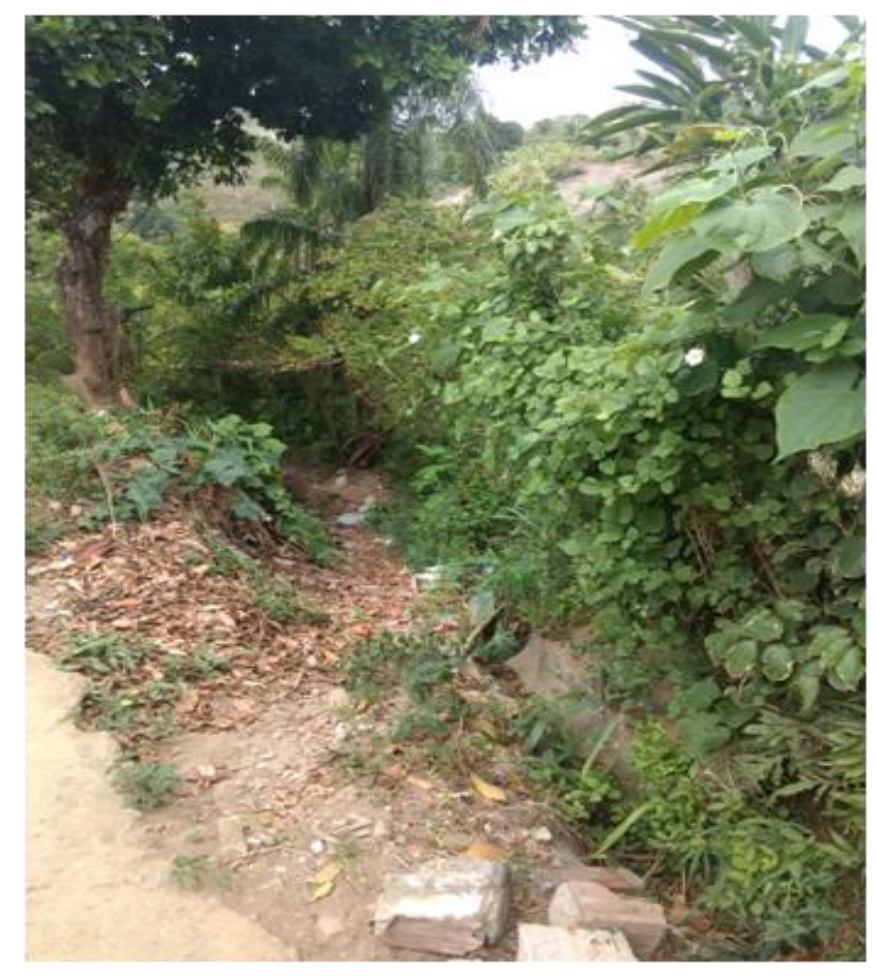

Fonte: Os autores.

Em vários pontos de uso residencial do alto curso da BHRP os arruamentos da localidade são direcionados à encosta, canalizando o fluxo hídrico, seja de águas servidas ou águas pluviais, intensificando o processo erosivo a partir do escoamento superficial. Assim, tais vias são propensas ao desenvolvimento de feições erosivas em decorrência da concentração de fluxo, podendo inviabilizá-las como via a partir do desenvolvimento de feições erosivas que podem comprometer a utilização de tais vias. 
ALMEIDA, J. D. M.; ROCHA, A. C. P.; SILVA, O.G.

Riscos geomorfológicos e sensitividade da paisagem na bacia hidrográfica do rio Paratibe (BHRP) - Região Metropolitana do Recife

Entretanto, apesar da baixa densidade ocupacional no alto curso da BHRP, existem moradias em locais de alto risco, devido a sua posição no topo da encosta de tabuleiros, sendo estas localizadas em elevada declividade e altura, apresentando-se, em alguns casos, no limite topo-encosta (Figura 4).

Por ser uma área que vem sofrendo uma intensificação de sua ocupação devido a expansão da franja urbana da RMR, tal ambiente demanda ações de planejamento e gestão ambiental e territorial antecipadas pelos poderes públicos constituídos visando a busca da minimização da ocupação destas áreas de fisiografia sensível a tais níveis e formas de ocupação, além da susceptibilidade destes ambientes a eventos erosivos e de movimentos de massa.

Figura 4 - Moradia no topo da borda de tabuleiro interfluvial no alto curso da BHRP (rua dos Mineiros, bairro de Aldeia dos Camarás, Camaragibe-PE)

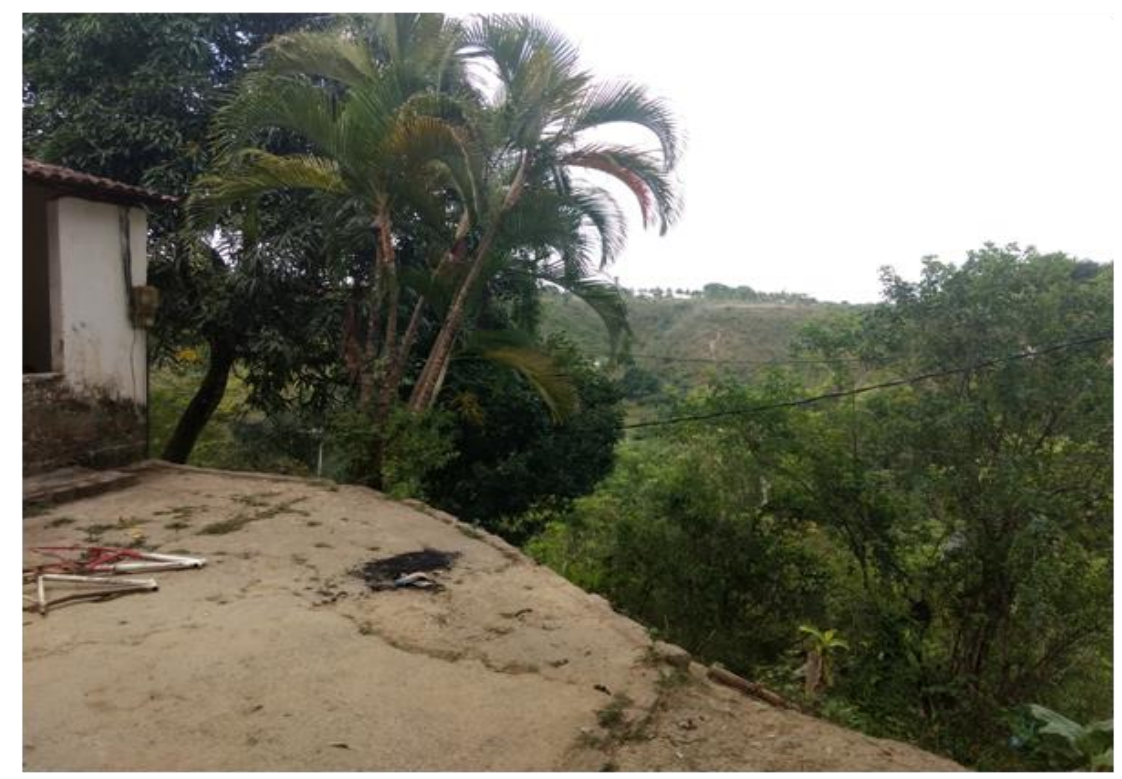

Fonte: Os autores.

Já na margem esquerda do curso superior da BHRP, em pontos onde não existe uma ocupação adensada, as bordas tabulares e encostas ainda estão preservadas, pois estão no interior do perímetro da Estação Ecológica de Caetés, que proibi a utilização da área para fins residenciais, minimizando os riscos e também resultando em proteção das cabeceiras/nascentes de cursos fluviais da bacia em tela. 
ALMEIDA, J. D. M.; ROCHA, A. C. P.; SILVA, O.G.

Riscos geomorfológicos e sensitividade da paisagem na bacia hidrográfica do rio Paratibe (BHRP) - Região Metropolitana do Recife

Enveredando na área de menor adensamento ocupacional no alto curso, e na transição para o médio curso do rio Paratibe, percebe-se uma mudança favorável aos níveis de ocupação da BHRP, certamente atrelados aos níveis de declividade, que deixam de ser limitantes para usos habitacionais (Figura 5). Em direção à foz, já na transição do médio para o baixo curso, ocorre um espraiamento de áreas de topografia plana, que representa uma diminuição da energia fluvial com a intensificação dos processos de sedimentação/deposição, propício a ocupações.

Figura 5 - Mapa de declividade da BHRP

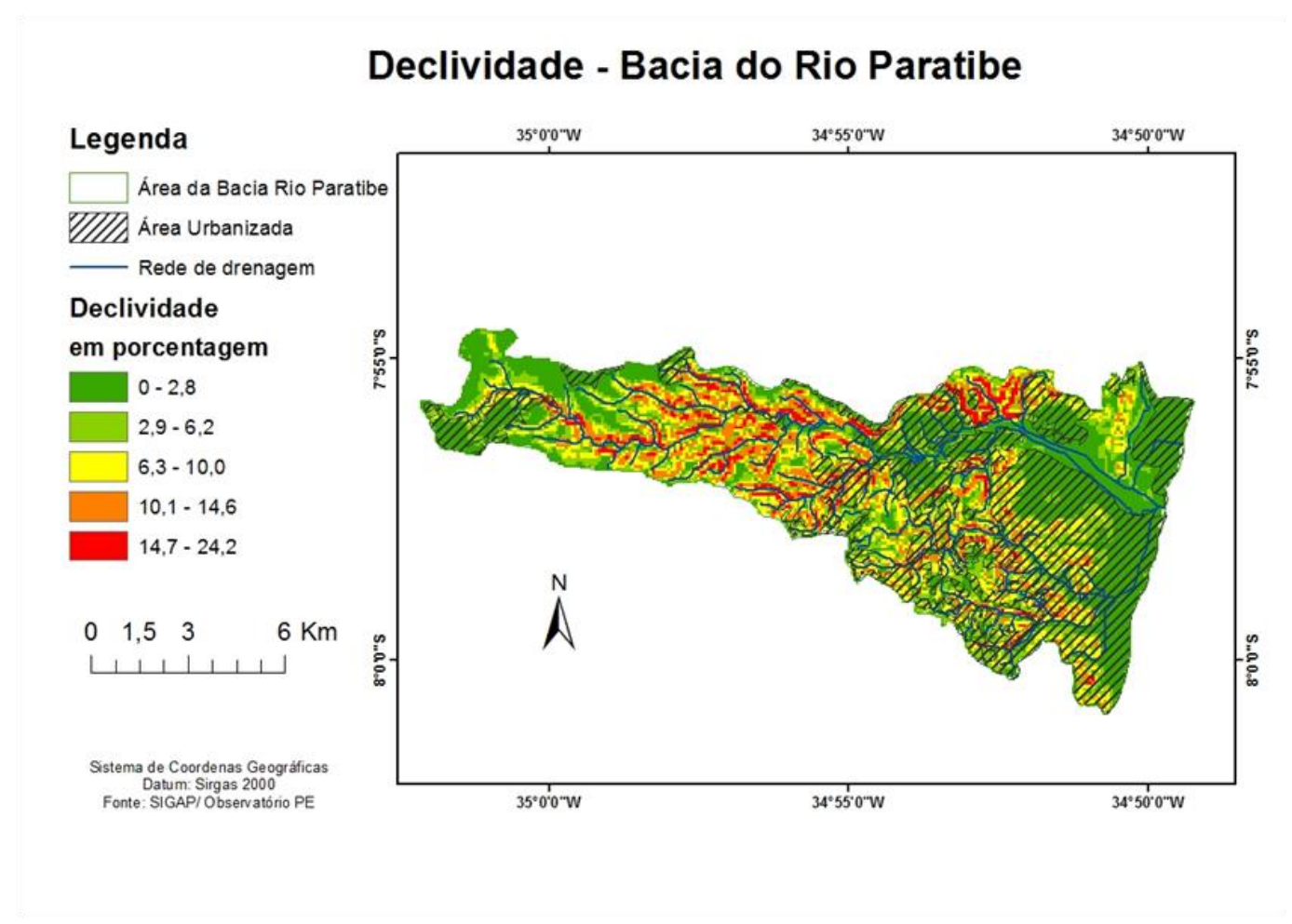

Fonte: Os autores.

Apesar de majoritariamente espraiada e plana, nessas áreas existem alguns pontos de maior elevação, como morros, colinas e tabuleiros da Formação Barreiras (CPRM, 2013), principalmente nos interflúvios da margem direita. Nesta parte da bacia a ocupação ocorre sem distinção de compartimentos, abarcando desde os topos, encostas e planícies.

A ocupação dos morros, colinas e tabuleiros neste segmento da bacia do rio Paratibe modifica a força de resistência do sistema devido a perturbação resultante da retirada 
ALMEIDA, J. D. M.; ROCHA, A. C. P.; SILVA, O.G.

Riscos geomorfológicos e sensitividade da paisagem na bacia hidrográfica do rio Paratibe (BHRP) - Região Metropolitana do Recife

da cobertura vegetação natural (Figura 6) e da progressiva impermeabilização das terras decorrente das formas de usos e ocupações.

Estes fatores alteram o processo de interceptação da chuva pelas copas vegetais, a fixação mecânica do solo pelos sistemas radiculares da vegetação e a plena promoção da infiltração da água, favorecendo o escoamento superficial, que resulta na intensificação do processo erosivo. De acordo com Souza (2014), esses processos erosivos, indiferentes do ponto onde ocorram, podem alterar a sensitividade da paisagem de forma generalizada, se propagando em várias direções, mesmo distante da área de origem (off-site).

Figura 6 - Encosta sem cobertura vegetal natural devido ao desmate. (vista da rua dos Mineiros, bairro de Aldeia dos Camarás, Camaragibe-PE)

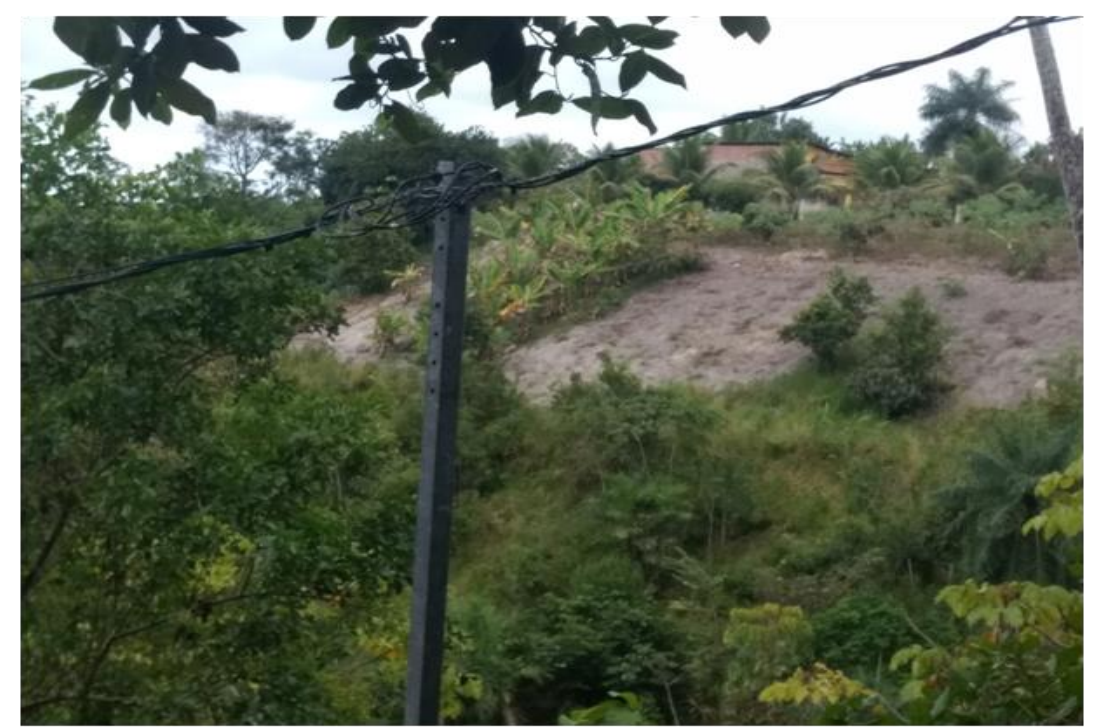

Fonte: Os autores.

Eventos naturais recorrentes no médio e baixo curso da bacia em questão são as enchentes e inundações que, dentre outras consequências, causam assoreamento dos canais como resultado da deposição do material erodido dos morros e colinas, assim como intervenções antrópicas realizadas em áreas interfluviais que contribuem para potencialização do escoamento. Estes eventos comuns na bacia do rio Paratibe atingem tanto o canal principal como os seus afluentes, como os canais do Fragoso e dos Bultrins, ambos no município de Olinda. 
ALMEIDA, J. D. M.; ROCHA, A. C. P.; SILVA, O.G.

Riscos geomorfológicos e sensitividade da paisagem na bacia hidrográfica do rio Paratibe (BHRP) - Região Metropolitana do Recife

As enchentes e inundação, assim como alagamentos, ocorrem exatamente nos pontos onde há uma maior acumulação do fluxo hídrico e ocupação adensada. Estas duas condições se interrelacionam, pois o aumento do fluxo é influenciado pela urbanização, já que ocorre a impermeabilização das superfícies e potencialização do escoamento superficial. Tais processos ocorrem mesmo em pontos em que a acumulação do fluxo não atinge os níveis mais elevados, destacados pelos pontos amarelos e azuis no mapa de acumulação de fluxo (Figura 7), o que decorre da maior interferência antrópica.

Figura 7 - Mapa de acumulação de fluxo

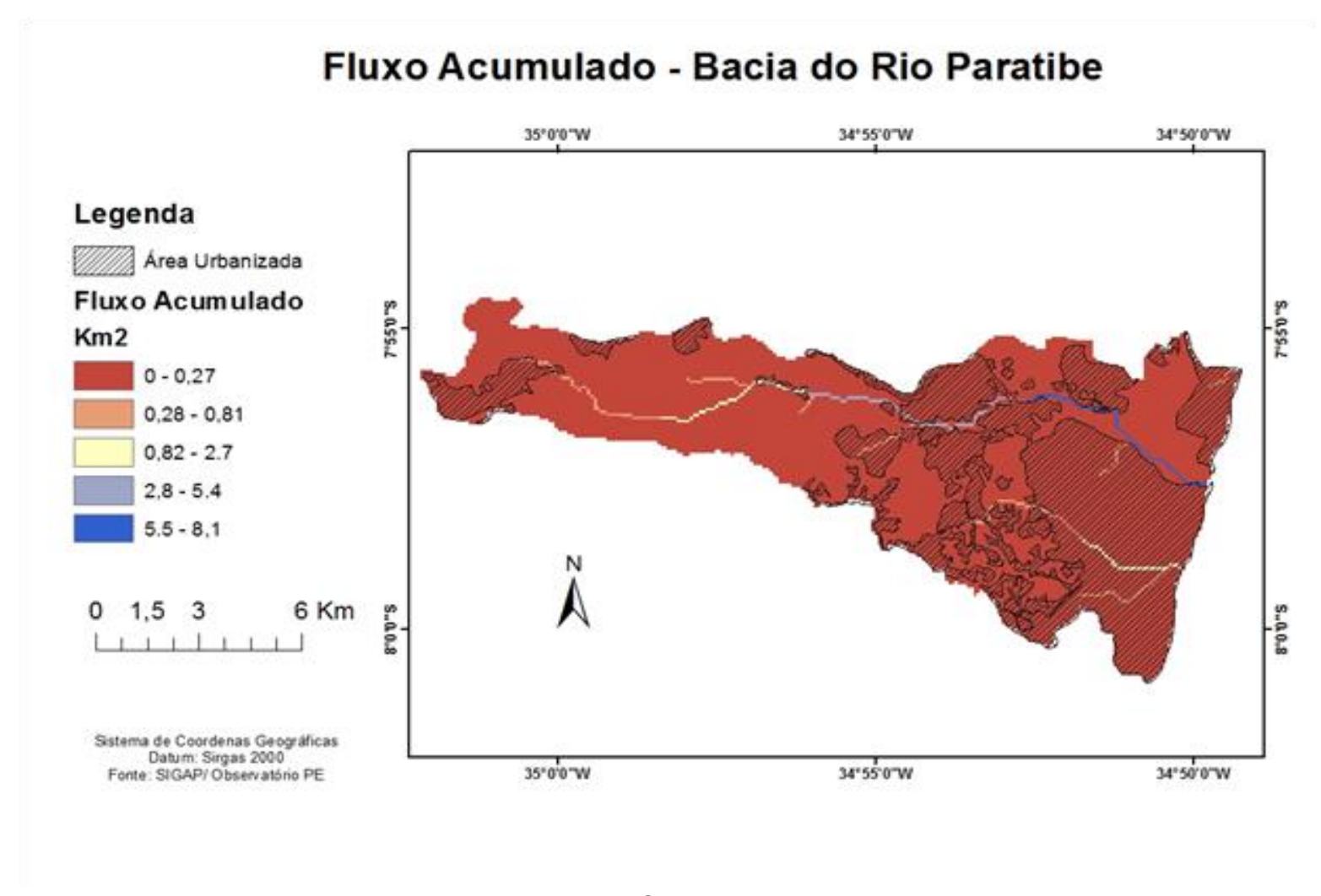

Fonte: Os autores.

Os pontos onde a acumulação de fluxo acarreta mais transtornos para a população ocorrem em áreas em que o nível de acumulação atinge entre 2,8 e 5,4 km² (área em azul claro), nas proximidades dos bairros de Paratibe e Paulista-Centro, e 0,82 e 2.7 km² (áreas em amarelo), nos bairros de Fragoso e Bultrins, que não são os níveis mais elevados, porém são os pontos onde existem maior ocupação das margens e dos leitos fluviais (Figura 8). 
ALMEIDA, J. D. M.; ROCHA, A. C. P.; SILVA, O.G.

Riscos geomorfológicos e sensitividade da paisagem na bacia hidrográfica do rio Paratibe (BHRP) - Região Metropolitana do Recife

Quanto aos domínios especificamente fluvial dos cursos presentes na bacia do rio Paratibe, as medidas tomadas pelo poder público para tentar sanar os problemas presentes não apresentam modificações significativas no comportamento do rio no relativo à dinâmica processual que reflete sobre as formas de ocupação. Medidas como retificação e canalização do rio aumentaram a vazão, contudo resultaram em efeitos contrários, principalmente quando são realizadas quebras bruscas na fluidez dos canais, como no caso do canal dos Bultrins, onde uma inflexão de $90^{\circ}$ de trecho canalizado potencializou eventos de inundações. Nestes pontos de inflexão, dependendo da intensidade da vazão, é normal haver o transbordamento mesmo quando da ocorrência de chuvas de moderada intensidade, atingindo o leito maior excepcional de rios onde, normalmente existem moradias e/ou eixos viários, como ocorre no caso do canal dos Bultrins.

Figura 8 - Ocupação dos terraços e leitos fluviais (canal dos Bultrins, rua Dr. Manoel de Barro Lima, bairro dos Bultrins, Olinda-PE)

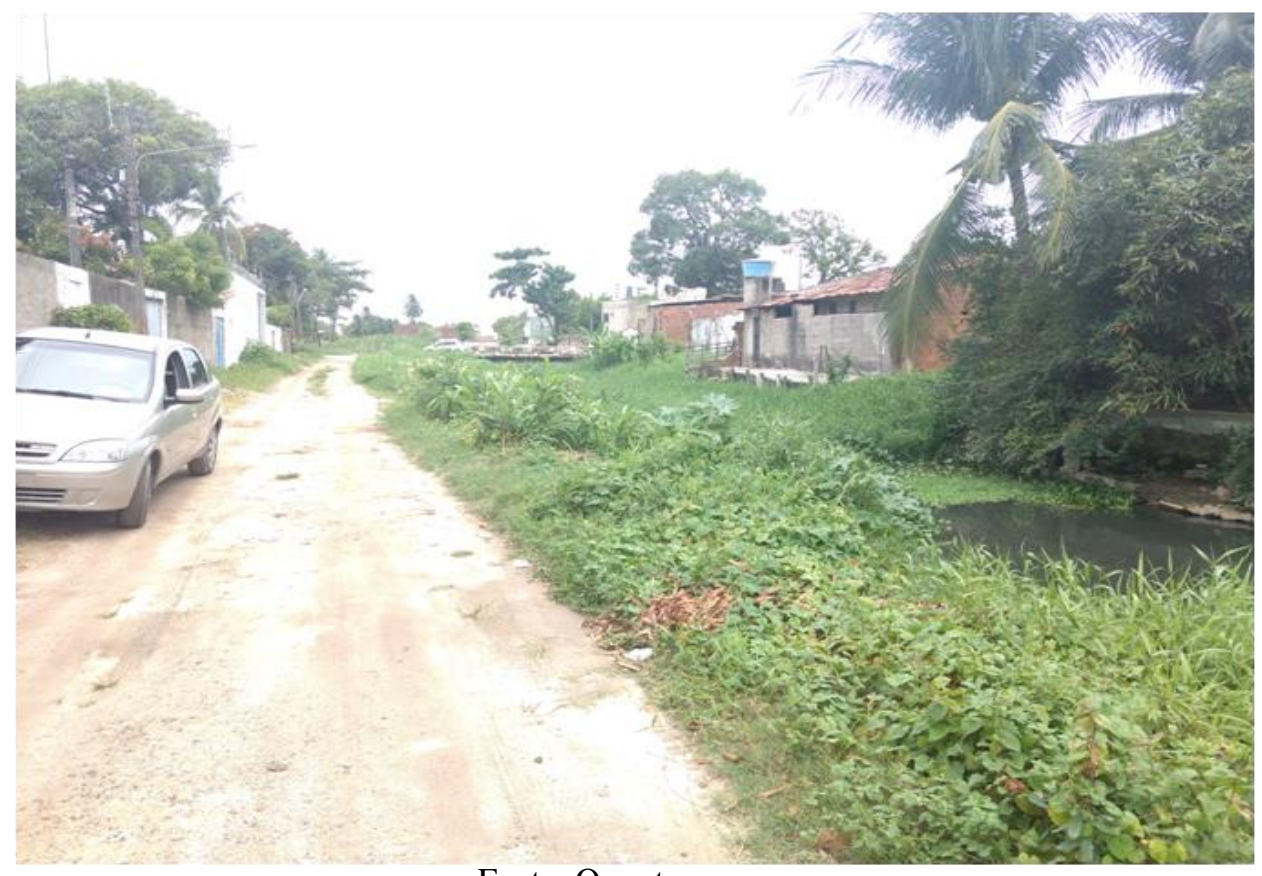

Fonte: Os autores.

As medidas pontuais, como retificação e canalização de canais fluviais, que aceleram a fluidez, não alteram de forma significativa os efeitos negativos resultantes das formas de usos e ocupações da terra ao longo de planícies fluviais e mesmo dos interflúvios. Efeitos como enchentes, inundações e alagamentos, além de processos erosivos e movimentos Revista Cerrados, Montes Claros/MG, v.16, n. 1, p. 103-129, jan./jun.-2018 
ALMEIDA, J. D. M.; ROCHA, A. C. P.; SILVA, O.G.

Riscos geomorfológicos e sensitividade da paisagem na bacia hidrográfica do rio Paratibe (BHRP) - Região Metropolitana do Recife

de massa, que constituem eventos naturais, tendem a serem intensificados, já que há um aumento considerável da urbanização, diminuindo áreas vegetadas e aumentando áreas impermeabilizadas, o que favorece o escoamento superficial.

Tendo em vista o que foi abordado, a bacia em tela, apesar de ser uma bacia de pequena dimensão e não ser ainda densamente ocupada em seu médio e alto curso, possui várias características naturais e de uso e ocupação que já resultam na susceptibilidade a perturbações do sistema natural, seja pela própria dinâmica processual implícita a ambiente, seja pelas formas de usos, que levam a susceptibilidades e vulnerabilidades da população a diferentes tipos de riscos.

Diante do exposto, foi visto que a análise da sensitividade da paisagem é uma ferramenta que pode auxiliar no estudo de áreas propensas a risco, pois a mesma baseia-se na percepção dos processos e formas de variados aspectos naturais e antrópicos. Desta forma, buscou-se com essa análise caracterizar o espaço sistemicamente, considerando interações de processos naturais e antrópicos, em que tais interações promovem uma dinâmica processual da paisagem, sendo tal análise útil para ações de planejamento e gestão ambiental e territorial voltadas para bacias hidrográficas inseridas em ambientes urbanos em expansão.

\section{CONSIDERAÇÕES FINAIS}

Os estudos sobre risco se tornam cada vez mais relevantes no processo de análise socioambiental, principalmente ao considerar as demandas ocupacionais de ambientes urbanos. A expansão urbana nas grandes cidades brasileiras, e mesmo nas regiões metropolitanas, pressiona o meio ambiente físico-natural, potencializando as consequências dos fenômenos climáticos, sobressaindo-se os pluviais extremos, transformando-os em eventos naturais geradores de eventos geomorfológicos intensificados promotores de perdas materiais e, eventualmente, de vidas humanas.

Dentro da perspectiva da análise do estudo do risco natural, a sensitividade da paisagem é uma "ferramenta" facilitadora na compreensão e avaliação do risco, já que a partir de uma análise conjuntural das características de uma determinada bacia hidrográfica pode-se alcançar como resultado a identificação do comportamento deste ambiente a partir de suas características naturais e do uso e ocupação da terra que se faz destes. Para tanto, o 
ALMEIDA, J. D. M.; ROCHA, A. C. P.; SILVA, O.G.

Riscos geomorfológicos e sensitividade da paisagem na bacia hidrográfica do rio Paratibe (BHRP) - Região Metropolitana do Recife

entendimento das dinâmicas processuais inerentes tantos ao domínio fluvial quanto o interfluvial, adicionando-se o componente perturbador destas relacionadas com as ações antrópicas decorrentes de variadas formas de ocupações se faz necessário.

No estudo em questão foram avaliadas as características topográficas da BHRP e as formas de uso e ocupação da terra, que resultaram no reconhecimento de que há áreas no perímetro da bacia hidrográfica e questão que estão sujeitas a determinados tipos de riscos, como erosão acelerada, movimentos de massa, enchentes e inundação. Por fim, observou que as medidas efetivadas pelo poder público são de caráter paliativo, as quais, devido a ações pontuais, não resolvem de forma efetiva os problemas existentes, e desconsideram a dinâmica processual dos ambientes físico-naturais.

\section{REFERÊNCIAS}

ALMEIDA, Joana D. Matias. Dinâmica e caracterização fluvial da bacia do Riacho Grande: abordagem da conectividade da paisagem. 52 f. Monografia (Graduação em Geografia). Curso de Bacharelado em geografia da Universidade Federal de Pernambuco UFPE, Recife. 2015.

AYALA, Irasema Alcântara. Geomorphology, natural hazards, vulnerability and prevention of natural desasters in developing countries. In: Geomorphology, n. 47. 107-124. 2002.

BITTAR, Omar Yazbek (Org.). Curso de Geologia Aplicada ao Meio Ambiente. São Paulo: Associação Brasileira de Geologia de Engenharia - Instituto de Pesquisa Tecnológica, Divisão de Geologia. 1995. 247 p.

BRUNSDEN, D.; THORNES, J. B. Landscape sensitivity and change. Transactions of the Institute of British Geographers, n. 4, p. 463-484, 1979.

BRUNSDEN, D. Barriers to geomorphological change. In: THOMAS, D. S. G.; ALISSON, R. J. Landscape sensisitivity. Chinchester: John Wiley \& Sons, 1993. 347 p.

BRUNSDEN, D. A critical assessment of the sensitivity concept in geomorphology. In:

Catena, v. 42, n. 2-4, p. 99-123. 2001.

CARVALHO, Luiz Eugênio. P. Os descaminhos das águas na metrópole: A socionatureza dos rios urbanos. 146 f. Tese (Doutorado em Geografia). Programa de Pós-Graduação em Geografia da Universidade Federal de Pernambuco - UFPE, Recife. 2011.

CASTRO, Susana D. Aneas de Riesgos y Peligros : Una visión desde la geografía. In: Scripta Nova - Revista Electrónica de Geografía y Ciencias Sociales, n 60, 15 de marzo de 2000. 
ALMEIDA, J. D. M.; ROCHA, A. C. P.; SILVA, O.G.

Riscos geomorfológicos e sensitividade da paisagem na bacia hidrográfica do rio Paratibe (BHRP) - Região Metropolitana do Recife

CHRISTOFOLETTI A. Geomorfologia. São Paulo: Edgard Blücher, 1980. 188 p.

COELHO NETTO, Ana. L. Hidrologia de encosta na interface com a geomorfologia. In: GUERRA, A. T.; CUNHA, S. B. Geomorfologia: uma atualização de bases e conceitos. 3 ed. Rio de Janeiro: Bertrand Brasil, p. 93-148. 1998.

CORRÊA, A. C. B. Contribuição à Análise do Recife como um Geossistema Urbano. In: Revista de Geografia. Recife: UFPE, v. 23, n. 3, p. 86-102. 2006.

Morfodinâmica e sensitividade ambiental dos ambientes semiáridos brasileiros: um enfoque a partir das relações solo x paisagem. In: Revista Portal do São Francisco, ano 5, n. 5, p. 51-65. 2006.

CUNHA, L.; DIMUCCIO, L. Considerações sobre riscos naturais num espaço de transição. Exercícios cartográficos numa área a Sul de Coimbra. In: Territorium, Coimbra, n. 9, p. 37 51. 2002.

CUNICO, Camila; OKA-FIORI, Chisato. O estado de normalidade e o estado de exceção diante da importância das categorias de "vulnerabilidade", "risco" e "resiliência". In:

Caminhos de Geografia: Uberlândia, v. 15, n. 52, p. 1-20. 2014.

FERNANDES, Nelson. F; GUIMARÃES, Renato Fontes; GOMES, Roberto Arnaldo Trancoso; VIEIRA, Bianca Carvalho; MONTGOMERY, David R.; GREENBERG, Harvey. Condicionantes geomorfológicos dos deslizamentos nas encostas: avaliação de metodologias e aplicação de modelo de previsão de áreas susceptíveis. In: Revista Brasileira de Geomorfologia, v. 2, n. 1, 51-71, 2001.

FREITAS, Carlos Machado; CARVALHO, Mauren Lopes de; XIMENES, Elisa Francioli; ARRAES, Eduardo Fonseca; GOMES, José Orlando. Vulnerabilidade socioambiental, redução de riscos de desastres e construção da resiliência: Lições do terremoto no Haiti e das chuvas fortes na Região Serrana , Brasil. In: Ciência \& Saúde Coletiva, 17 (6), 1577-1586, 2012.

GARCIA, R. A. C.; ZÊZERE, J. L. Avaliação de Riscos Geomorfológicos: conceitos, terminologia e métodos de análise. In: III Seminário de Recursos Geológicos, Ambiente e Ordenamento do Território, Vila real, Portugal, p. 299-308. 2003.

GIRÃO, Osvaldo; CORRÊA, Antonio Carlos de Barros; GUERRA, Antonio José Teixeira. Influência da climatologia rítmica sobre áreas de risco: O caso da Região Metropolitana do Recife para os anos de 2000 e 2001. In: Revista de Geografia. Recife: UFPE, v. 23, n. 1, p. 3-40. 2006.

GIRÃO, Osvaldo; CORRÊA, Antonio Carlos de Barros; NÓBREGA, Ranyére da Silva; DUARTE, Cristiana Coutinho. O Papel do Clima nos Estudos de Prevenção e Diagnóstico de Riscos Geomorfológicos em Bacias Hidrográficas na Zona da Mata Sul de Pernambuco. In: GUERRA, Antonio José Teixeira e OLIVEIRA JORGE, Maria do Carmo (Orgs), Erosão e 
Riscos geomorfológicos e sensitividade da paisagem na bacia hidrográfica do rio Paratibe (BHRP) - Região Metropolitana do Recife

Movimentos de Massa: Recuperação de Áreas Degradadas e Prevenção de Acidentes. São Paulo: Oficina de Textos, p. 126-159. 2013.

GUERRA, Antonio José Teixeira. O início do processo erosivo. In: GUERRA, Antonio José Teixeira; SILVA, Antonio Soares da; BOTELHO, Rosângela Garrido Machado. (Orgs). Erosão e conservação dos solos: Conceitos, temas e aplicações. Rio de Janeiro: Bertrand Brasil, p. 17-56. 1999.

GUPTA, Avijit e AHMAD, Rafi. Geomorphology and the urban tropics: Building na interface between research and usage. In: Geomorphology, n. 31. 133-149. 1999.

HÉTU, Bernard. Uma geomorfologia socialmente útil: os riscos naturais em evidência. In: Mercator: Revista de Geografia da UFC, vol. 2, n. 3, p. 83-97. 2003.

HORA, Silmara. B.; GOMES, Ronaldo. L. Mapeamento e avaliação do risco de inundação do rio Cachoeira em trecho da área urbana do município de Itabuna/BA. In: Sociedade $\&$ Natureza: Uberlândia, 21 (2), p. 57-75. 2009.

MATTOS, Sérgio Henrique Vannucchi Lemes de; PEREZ FILHO, Archimedes. Complexidade e estabilidade em sistemas geomorfológicos: uma introdução ao tema. In: Revista Brasileira de Geomorfologia, vol. 5, n. 1, p. 11-18. 2004.

MOURA, Rosa; SILVA, Luís Antonio de Andrade e. Desastres naturais ou negligência humana? In: Revista Geografar: Curitiba, v. 3, n. 1, p. 58-72, 2008.

PHILLIPS, Jonathan D. The end of equilibrium? In: Geomorphology, 5 (3-5), p. 195-201, 1992.

PHILLIPS, Jonathan D. Changes, pertubations, and responses in geomorphic systems. In: Progress in Physical Geography, 33 (1), p. 17-30, 2009.

RAMOS, Catarina. Perigos naturais devidos a causa meteorológicas: o caso das cheias e inundações. In: E-LP Engeneering and Technology Journal, v. 4, p. 11-16. 2013.

ROCHA, Antonio Carlos da Paz. Análise morfodinâmica e morfogenética do interflúvio do médio curso da margem direita do Rio Beberibe. $124 \mathrm{f}$. Dissertação (Mestrado em Geografia). Programa de Pós-graduação em Geografia da Universidade Federal de Pernambuco - UFPE, Recife. 2013

SILVA, Carla. S.; BISPO, Carlos. O.; SANTANA, Gabriel. A. C.; GIRÃO, Osvaldo Deslizamentos e enchentes na bacia do rio Tejipió: Percepção e resiliência frente a riscos geomorfológicos. In: Revista OKARA: Geografia em debate (UFPB), v. 11, p. 316-337, 2017.

SOUZA, Jonas Otaviano P. Sistema fluvial e açudagem no semi-árido, relação entre a conectividade da paisagem e dinâmica da precipitação, na bacia de drenagem do riacho do saco, Serra Talhada, Pernambuco. 169 f. Dissertação (Mestrado em Geografia) 
ALMEIDA, J. D. M.; ROCHA, A. C. P.; SILVA, O.G.

Riscos geomorfológicos e sensitividade da paisagem na bacia hidrográfica do rio Paratibe (BHRP) - Região

Metropolitana do Recife

Programa de Pós-Graduação em Geografia da Universidade Federal de Pernambuco - UFPE, Recife. 2011.

SOUZA, Jonas Otaviano P. Modelos de evolução da dinâmica fluvial em ambiente semiárido: Bacia do Riacho do Saco, Serra Talhada, Pernambuco. 189 f. Tese (Doutorado em Geografia) Programa de Pós-Graduação em Geografia da Universidade Federal de Pernambuco - UFPE, Recife. 2014.

SUGUIO Kenitiro. Geologia Sedimentar. São Paulo: Edgard Blücher, 2003. 400 p.

SUGUIO, Kenitiro. Geologia do Quaternário e mudança ambientais. 2 ed. São Paulo: Oficina de Textos, 2010. 408 p.

THOMAS, Michael F. Landscape sensitivity in time and space: an introduction. Catena, n. 42, p. 83-98, 2001.

VEYRET, Yvette. Os Riscos: O homem como agressor e vítima do meio ambiente. São Paulo: Contexto, 2007. 319 p.

\section{Autores}

Joana D'arc Matias de Almeida - Possui Graduação e Mestrado em Geografia, ambos cursados pela Universidade Federal de Pernambuco (UFPE). Atualmente é Doutorando pelo Programa de Pós-Graduação em Geografia da Universidade Federal de Pernambuco (UFPE).

Antonio Carlos da paz Rocha - Possui Graduação e Mestrado em Geografia, ambos cursados pela Universidade Federal de Pernambuco (UFPE). Atualmente é Doutorando pelo Programa de Pós-Graduação em Geografia da Universidade Federal de Pernambuco (UFPE).

Osvaldo Girão da Silva - Possui Graduação e Mestrado em Geografia, ambos cursados pela Universidade Federal de Pernambuco (UFPE) e Doutorado em Geografia pela Universidade Federal do Rio de Janeiro (UFRJ). Atualmente é Professor do Programa de Pós-Graduação em Geografia da Universidade Federal de Pernambuco (UFPE).

Artigo recebido em: 27 de abril de 2018.

Artigo aceito em: 04 de junho de 2018.

Artigo publicado em: 30 de junho de 2018 . 